\title{
A viscoelastic model for the long-term deflection of segmental prestressed box girders
}

\author{
Angela Beltempo, Oreste S. Bursi*, Carlo Capello, Daniele Zonta \\ Department of Civil, Environmental and Mechanical Engineering (University of Trento), Via Mesiano 77, 38123 Trento, Italy
}

\&

\begin{abstract}
Massimiliano Zingales
Department of Civil, Environmental, Aerospace, Materials Engineering (University of Palermo), Viale delle Scienze Ed.8, 90128 Palermo, Italy
\end{abstract}

Abstract: Most of segmental prestressed concrete box girders exhibit excessive multidecade deflections unforeseeable by past and current design codes. In order to investigate such a behavior, mainly caused by creep and shrinkage phenomena, an effective FE formulation is presented in this paper. This formulation is developed by invoking the stationarity of an energetic principle for linear viscoelastic problems and relies on the Bazant creep constitutive law. A case study representative of segmental prestressed concrete box girders susceptible to creep is also analyzed in the paper, i.e. the Colle Isarco viaduct. Its FE model, based on the aforementioned energetic formulation, was successfully validated through the comparison with monitoring field data. As a result, the proposed ID FE model can effectively reproduce the past behavior of the viaduct and predict its future behavior with a reasonable run time, which represents a decisive factor for the model implementation in a decision support system.

$\begin{array}{cl}\text { Nomenclature } \\ A & \text { cross section area } \\ \mathbf{C} & \text { costs } \\ C_{0}\left(t, t^{\prime}\right) & \text { compliance function for basic creep } \\ C_{d}\left(t, t^{\prime}, t_{0}\right) & \text { compliance function for drying } \\ \boldsymbol{D} & \text { derivative operator } \\ E_{28} & \text { Young's modulus at 28 days } \\ F(u, v) & \text { extension of the total potential energy } \\ \boldsymbol{H} & \text { operator of the assembled structure } \\ I & \text { momentum of inertia } \\ J_{B 3}\left(t, t^{\prime}\right) & \text { compliance function of Model B3 } \\ \boldsymbol{K} & \text { elastic stiffness operator } \\ \boldsymbol{L} & \text { extended stiffness operator } \\ L & \text { beam length } \\ \boldsymbol{M}(t) & \text { operator of time shape functions }\end{array}$

$\begin{array}{cl}\boldsymbol{N}(x) & \text { operator of spatial shape functions } \\ R\left(x, t^{\prime}, t^{\prime}\right) & \text { generic relaxation function evaluated at } \\ & t^{\prime} \\ R_{B 3}\left(t, t^{\prime}\right) & \text { relaxation function of Model B3 } \\ a_{\mathrm{opt}} & \text { economically optimal choice } \\ a / c & \text { aggregate-cement ratio } \\ \boldsymbol{f} & \text { vector of nodal forces } \\ \overline{f_{c}} & \text { cylinder compression strength } \\ \boldsymbol{g} & \text { extended vector of equivalent nodal } \\ & \text { forces } \\ i & \text { index to indicate the generic iteration } \\ & \text { step } \\ p(x, t) & \text { index to indicate the current time step } \\ p(\boldsymbol{\theta}) & \text { longitudinal distributed load } \\ p(S) & \text { prior probability of parameter } \\ & \text { prior probability of possible structural } \\ \hat{p}(x, t) & \text { conditions } \\ q(x, t) & \text { fictitious longitudinal distributed load } \\ \hat{q}(x, t) & \text { transversal distributed load } \\ q_{1} & \text { fictitious transversal distributed load } \\ q_{2} & \text { first parameter of Model B3 } \\ q_{3} & \text { second parameter of Model B3 } \\ q_{4} & \text { third parameter of Model B3 } \\ q_{5} & \text { forth parameter of Model B3 } \\ \boldsymbol{r}(t) & \text { fifth parameter of Model B3 } \\ \boldsymbol{r}_{\boldsymbol{u}} & \text { vector of nodal DoFs } \\ \boldsymbol{r}_{\boldsymbol{v}} & \text { vector of extensional DoFs } \\ t & \text { vector of bending DoFs } \\ t_{0} & \text { timeneric time } \\ t^{\prime} & \text { loading time } \\ u(x, t) & \text { longitudinal displacement } \\ & \\ & \\ & \end{array}$




\begin{tabular}{|c|c|}
\hline$\hat{u}(x, t)$ & $\begin{array}{l}\text { fictitious longitudinal displacement of } \\
\text { the auxiliary elastic problem }\end{array}$ \\
\hline$v(x, t)$ & transversal displacement \\
\hline$\hat{v}(x, t)$ & $\begin{array}{l}\text { fictitious transversal displacement of the } \\
\text { auxiliary elastic problem }\end{array}$ \\
\hline$w / c$ & water-cement ratio \\
\hline$x$ & beam longitudinal axis \\
\hline $\mathbf{y}$ & SHM measurements \\
\hline$\Delta T$ & temperature variation \\
\hline$\alpha$ & thermal expansion coefficient \\
\hline $\boldsymbol{\alpha}(t)$ & vector of spatial displacement unknowns \\
\hline$\widehat{\boldsymbol{\alpha}}(t)$ & $\begin{array}{l}\text { vector of fictitious displacement } \\
\text { unknowns }\end{array}$ \\
\hline $\boldsymbol{\beta}$ & vector of time displacement unknowns \\
\hline$\varepsilon(t)$ & total strain evaluated at time $\mathrm{t}$ \\
\hline$\varepsilon^{c r}$ & creep strain \\
\hline$\varepsilon_{s h}(t)$ & shrinkage strain evaluated at time $t$ \\
\hline$\varepsilon_{s h \infty}$ & shrinkage strain at infinity \\
\hline$\epsilon$ & tolerance vector \\
\hline$\sigma$ & constant stress \\
\hline $\boldsymbol{\theta}$ & vector of generic parameters \\
\hline
\end{tabular}

\section{INTRODUCTION}

\subsection{Background and motivation}

"Clarification of the causes of major disasters and serviceability losses has been, and will always be, a prime opportunity for progress in structural engineering" (Bazant et al., 2012). This need always arises behind important upgrades in design codes and is followed by many researchers for a better understanding of complex phenomena.

According to that need, this study will cover a specific class of bridges, i.e. prestressed concrete box girders, which reveal excessive multidecade deflections unforeseeable by past and current design codes. For instance, let us examine the Koror-Babelthuap Bridge in Palau, depicted in Figure 1(a)-(b), which collapsed in 1996 mainly due to an excessive creep deflection recorded at midspan; or other four segmental prestressed box girders in Japan, which exhibited a similar behavior (Koshirazu, Tsukiyono, Konaru, and Urado) (Bazant et al., 2012). An example in Europe, proving once more that the multidecade deflections are not unique occurrences for the Koror-Babelthuap Bridge, is represented by the Colle Isarco viaduct, shown in Figure 1(c)-(d), which still constitutes a strategic link in the highway corridor connecting Northern Italy with Germany.

Specifically, the excessive multidecade deflections of the aforementioned box girders and many others bridges spread throughout the world may be due to the combination of several factors (Beltempo et al., 2015) listed herein: i) the cast-in-place segmental method used for construction; ii) creep deformation; iii) losses of pretensioning force in tendons; and iv) differential shrinkage between top and bottom slabs. However, with regard to the Colle Isarco viaduct, i.e. the case study of this paper, any attempt to investigate the midspan deflection drift using the classical CEB-FIP creep and shrinkage models (CEB, 2008) -those currently recognized by Eurocode 2 (CEN, 2004)- failed to provide a convincing explanation/prediction. In fact, according to the CEB-FIP model, creep effects become negligible 20 years after concrete casting, whilst the Colle Isarco viaduct experiences a deflection still growing 40 years after its construction. Thus, the hyperbolic law exploited in Eurocode 2 creep models clearly exhibits limitations to its applicability. Bazant et al. (2012), focusing on KororBabelthuap Bridge, also demonstrated that classical CEBFIP shrinkage and creep models are clearly not suited for reproducing the long-term deflection of large-span segmentally-erected box girders and recommended the use of creep Model B3 (Bazant \& Baweja, 1995), which has been recently improved in Model B4 (Wendner et al., 2015). Unlike CEB-FIP models, both Model B3 and Model B4 consider a creep component whose effect persists even many decades after concrete casting. Moreover, they properly take into account difference in shrinkage between top and bottom slabs of the box girder, a phenomenon that could strongly influence the deflection trend. Model B4 includes two major improvements with respect to Model B3: the first is the inclusion of temperature effects in the creep function; the second concerns the separation of the drying and the autogenous components of shrinkage, particularly important for high strength concrete.

An innovative approach to investigate excessive deflections in massive concrete structures could be the introduction of fractional (real-order) operators into the creep constitutive law (Di Paola \& Zingales, 2012, Di Paola et al., 2013). Specifically, the use of fractional operators could bring significant computational savings to model calibration due to the reduced number of parameters -about three- involved into the formulation. However, both Di Paola \& Zingales (2012) and Di Paola et al. (2013) applied fractional operators to hereditary materials, e.g. polymers, and not to ageing materials like concrete. Therefore, in this research work we focus on Model B3 mainly because its creep and relaxation functions (Bazant \& Baweja,1995, Bazant et al.,2013), can be fitted by fractional operators. Moreover, a reliable relaxation function is not yet available for Model B4 and, therefore, Model B3 is preferred. 
Significant aspects relative to monitoring and modelling of segmental box girders should worthy of investigation. In fact, in most cases, the inexplicable behavior of this specific class of structures led to the installation of efficient structural health monitoring (SHM) systems and to the development of FE models. This is the case of the Colle Isarco viaduct, for which both field data -revealed to assess the effectiveness of the last maintenance work undertaken in 2014- and FE model predictions were used to provide information on future structural performance and to support decisions concerning the viaduct management. The SHM system installed on the Colle Isarco viaduct includes: i) fiberoptic sensors based on fiber Bragg gratings (Balageas $e t$ al., 2010; Glisic \& Inaudi 2007) to measure strains of top and bottom slabs; ii) PT100 resistance thermometers to acquire temperature variations along the whole structure; and iii) a topographic network with prisms to measure displacements. This fusion of data coming from different sensors certainly reduces uncertainties regarding structural behavior (Han et al., 2017), helps the bridge manager to identify causes of possible anomalies and improves his or her capability to take optimal decisions (Cappello et al., 2016).

As further support for computational frameworks for Bayesian inference and bridge maintenance decisions, a 1D FE model of the Colle Isarco viaduct, which is presented in this paper, was also developed. Along the same lines, Caracoglia et al. (2009) developed a timedomain FE model to better interpret the behavior of longspan modern bridges under vortex shedding-induced loads. Torbol et al. (2013) used a FE analysis to evaluate bridge fragility throughout its service life. Shapiro (2007) built a FE model of the Interstate Highway 565 Bridge in Huntsville (Alabama), to investigate the main causes of cracking phenomena observed just after the construction of the bridge. The main difference between the aforementioned models and the model of the Colle Isarco viaduct is that they are all available in commercial software, mainly ANSYS or OpenSEES (Mazzoni, 2006); conversely, the Colle Isarco's model is implemented in MATLAB and relies on an energetic formulation for linear viscoelastic problems (Carini et al., 1995). Another important aspect is its reduced run time, which is determinant for both stochastic computations and model implementation in a Decision Support System (DSS). In sum, to the authors' knowledge, there is a paucity of papers dealing with modelling of creep and shrinkage phenomena for simple yet effective FE simulations of complex segmental prestressed concrete box girders; box girders that, in addition, are subjected to complex loading histories. These are the important issues that the paper explores further.

\subsection{Scope}

This paper presents the main issues regarding the modelling of creep and shrinkage phenomena for a specific class of bridges, i.e. segmental prestressed concrete box girders subjected to complex loading histories. It also shows how a reliable SHM system coupled to an effective FE model can be used to investigate the past behavior and predict the short- and long-term deflection of such complex structures, considering, as representative case study, the Colle Isarco viaduct.

According to this aim, we organize the paper as follows. Firstly, Section 2 describes an energetic formulation and a creep constitutive law suitable for the problem under investigation. Section 3 introduces a segmental prestressed concrete box girder, i.e. the Colle Isarco viaduct, focusing on the main structural characteristics and the SHM system installed on the viaduct in 2014. Section 4 provides details about the implementation of the viaduct geometry and the whole load history into the FE formulation, together with model results. Moreover, an overview of the conceived DSS as further development of this research work can be found in Section 5. Finally, we present conclusions and future developments in Section 6.

\section{A FE FORMULATION FOR PRESTRESSED CONCRETE BOX GIRDERS}

In this section, we propose an effective way to model segmental prestressed concrete box girder deflection and, generally, all structures highly sensitive to creep, without resorting to commercial software analyses. Hence, we present a 1D FE formulation by invoking the stationarity of a functional for linear viscoelastic problems, which relies on the creep constitutive law of Bazant (Bazant \& Baweja, 1995).

Hereinafter, we recall the Bazant's creep law, known in the literature as Model B3 (Bazant \& Baweja, 1995); and present, in greater detail, an energetic formulation for concrete (aging) materials derived from a previous formulation proposed by Carini et al. (1995).

\subsection{A constitutive creep model: Model B3}

In its most general form, Model B3 (Bazant \& Baweja, 1995 ) assumes that, for a constant stress $\sigma$ applied at age $t^{\prime}$, the resulting strain $\varepsilon(t)$ at time $t$ can be expressed as

$$
\varepsilon(t)=J_{B 3}\left(t, t^{\prime}\right) \cdot \sigma+\varepsilon_{s h}(t)+\alpha \cdot \Delta T(t)
$$




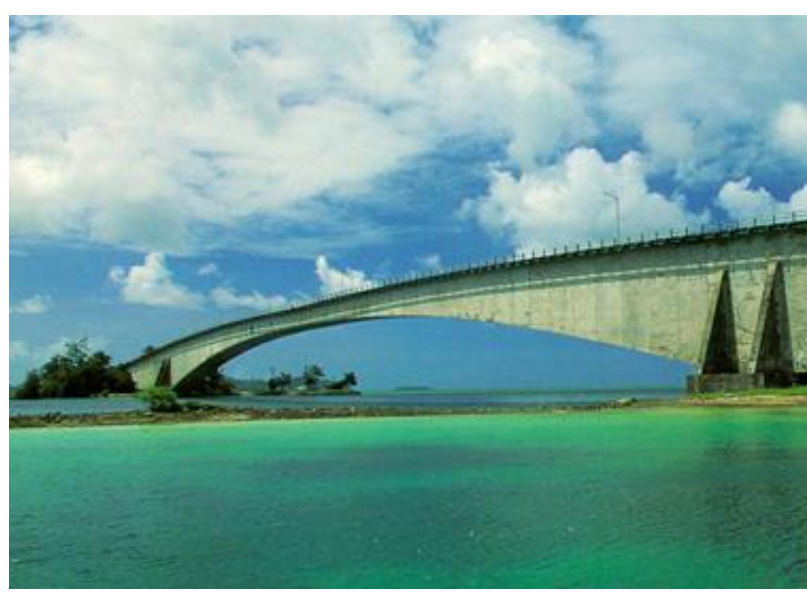

a)

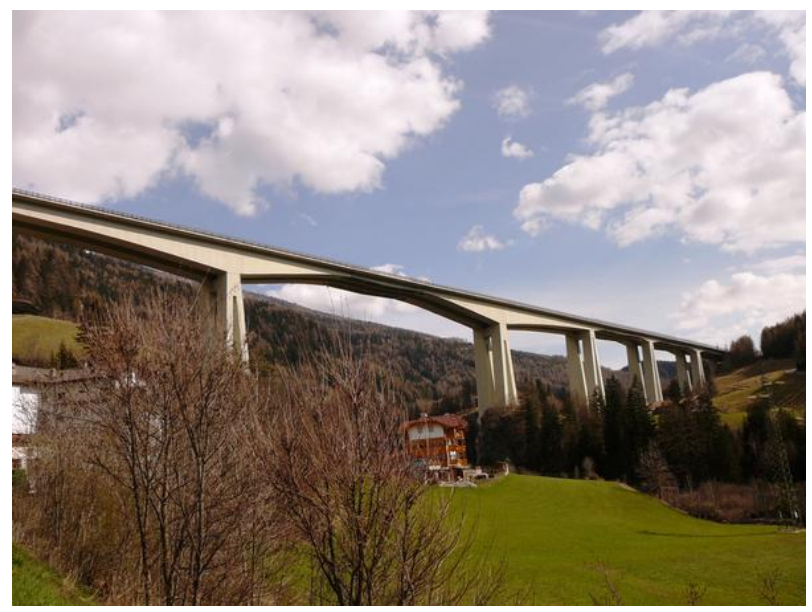

c)

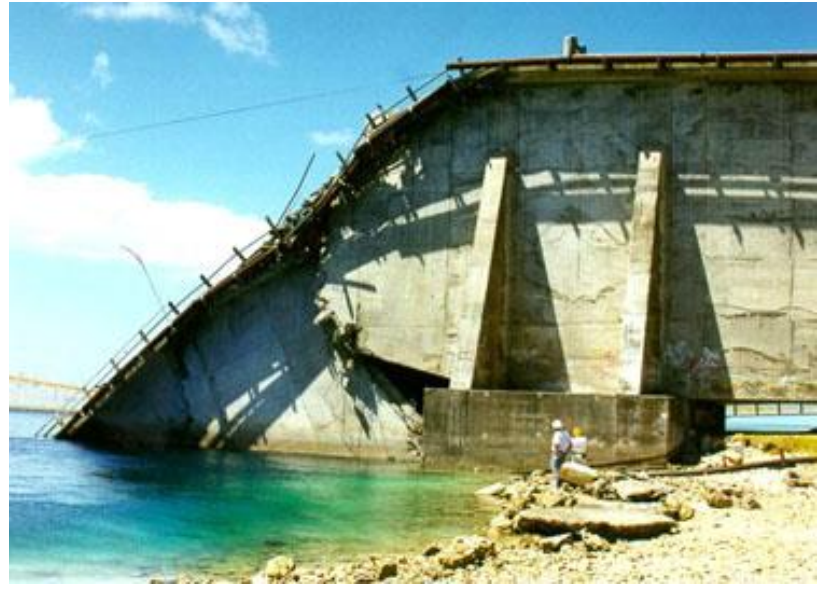

b)

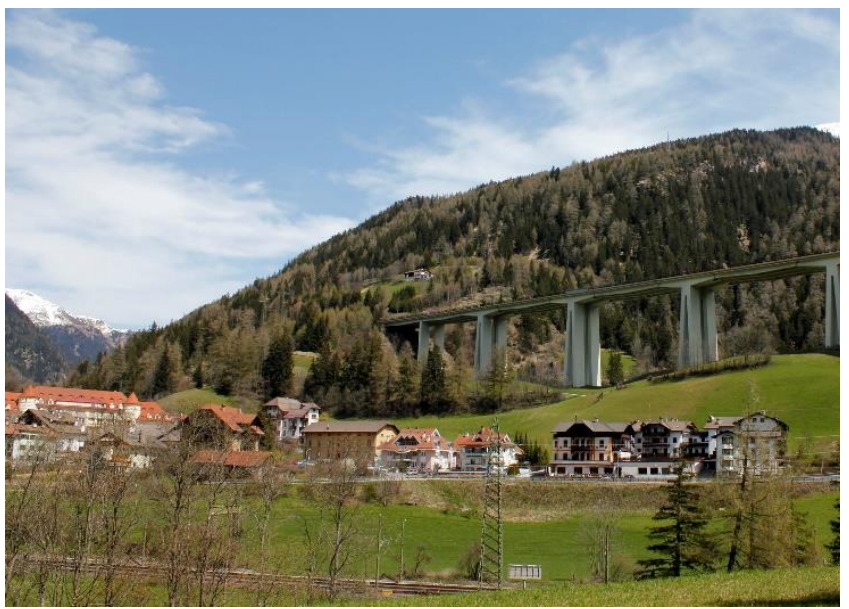

d)

Figure 1. (a) The Koror-Babelthuap Bridge in Palau; (b) the Koror-Babelthuap Bridge failure;

(c) the central span of the Colle Isarco viaduct in Italy; (d) northern lateral spans of the Colle Isarco viaduct

in which $J_{B 3}\left(t, t^{\prime}\right)$ defines the compliance function, i.e. strain at time $t$ caused by a unit uniaxial constant stress at $t^{\prime}, \varepsilon_{s h}$ is the shrinkage strain, $\Delta T$ defines the temperature variation, and $\alpha$ the thermal expansion coefficient. Furthermore, we can conceive the compliance function as the sum of three components,

$$
J_{B 3}\left(t, t^{\prime}\right)=q_{1}+C_{0}\left(t, t^{\prime}\right)+C_{d}\left(t, t^{\prime}, t_{0}\right)
$$

where $q_{1}$ defines the instantaneous strain due to a unit stress, $C_{0}$ is the compliance function for basic creep, meaning the creep at constant moisture content and no moisture movement through the material, and $C_{d}$ defines the compliance function for drying starting at time $t_{0}$.

The basic creep compliance can be further broken down into

$$
\begin{aligned}
& \quad C_{0}\left(t, t^{\prime}\right)=q_{2} Q\left(t, t^{\prime}\right)+q_{3} \ln \left[1+\left(t-t^{\prime}\right)^{n}\right]+ \\
& q_{4} \ln \left(\frac{t}{t^{\prime}}\right)
\end{aligned}
$$

where function $Q$ is discussed in more detail in Bazant \& Baweja (1995). The terms in (3) containing $q_{2}, q_{3}, q_{4}$ represent the aging viscoelastic compliance, non-aging viscoelastic compliance and flow compliance, respectively, as deduced from the solidification theory. The drying compliance $C_{d}$ reads

$$
C_{d}\left(t, t^{\prime}, t_{0}\right)=q_{5}\left[e^{-8 H(t)}-e^{-8 H\left(t_{0}^{\prime}\right)}\right]^{1 / 2}
$$

where $H$ is the hydraulic radius of the section, i.e. the volume-to-surface ratio and $t_{0}^{\prime}=\max \left(t^{\prime}, t_{0}\right)$. Evidently, 
Equation (4) is valid for $t>t_{0}^{\prime}$, otherwise it is equal to zero. The five parameters of Model B3 can be either treated as statistical variables or estimated through the following formulas, valid only for certain ranges of material mechanical properties (Bazant \& Baweja, 1995), i.e.

$$
\begin{aligned}
& q_{1}=0,6 \cdot 10^{6} E_{28} \quad E_{28}=4734 \sqrt{\bar{f}_{c}} \\
& q_{2}=185.4 c^{0.5} \bar{f}_{c}^{-0.9} \\
& q_{3}=0.29(w / c)^{4} q_{2} \\
& q_{4}=20.3(a / c)^{-0.7} \\
& q_{5}=7.57 \cdot 10^{5} \bar{f}_{c}^{-1}\left|\varepsilon_{s h \infty}\right|^{-0.6}
\end{aligned}
$$

All the formulas above are given in SI (metric) units (MPa, m). In addition, $E_{28}$ is the Young's modulus at 28 days, $\bar{f}_{c}$ defines the cylinder compression strength, $w / c$ is water-cement ratio, $a / c$ is aggregate-cement ratio, and $\varepsilon_{s h \infty}$ is the shrinkage strain at infinity.

Once the compliance function and its five parameters are known, it is also possible to estimate the corresponding relaxation function $R_{B 3}$ through the following approximate formula (Bazant et al., 2013):

$$
R_{B 3}\left(t, t^{\prime}\right)=\frac{1}{J_{B 3}\left(t, t^{\prime}\right)}\left[1+\frac{c_{1} \alpha\left(t, t^{\prime}\right) J_{B 3}\left(t, t^{\prime}\right)}{q J_{B 3}(t, t-\eta)}\right]^{-q}
$$

where

$$
\begin{array}{ll}
c_{1}=0.0119 \ln \left(t^{\prime}\right)+0.08 & q=10 \\
\alpha\left(t, t^{\prime}\right)=\frac{J\left(t^{\prime}+\epsilon, t^{\prime}\right)}{J(t, t-\epsilon)}-1 & \\
\epsilon=\frac{t-t^{\prime}}{2} & \eta=1
\end{array}
$$

Unlike the formula developed in 1979 by Bazant and Kim (Bazant \& Kim, 1979), Equation (10) prevents any violation of the thermodynamic requirement of negatives of $R_{B 3}\left(t, t^{\prime}\right)$. Therefore, (10) can be utilized to describe the long-time relaxation phenomenon of concrete loaded at a young age; for this reason, it is particularly useful for compliance functions that correctly describe multidecade creep, which is the case of the Model B3 compliance function.

In summary, Model B3 depends on five different terms, controlled by parameters $q_{1}, q_{2}, q_{3}, q_{4}$, and $q_{5}$. The first three components roughly reproduce the same effect as the classical CEB-FIP model (CEB, 2008) and have no impact on the long-term behavior. In contrast, the flow compliance term, including $q_{4}$, is unique to Model B3 and to the aforementioned Model B4 (Wendner et al., 2015); it depends on the logarithm of time and, thus, keeps producing its effects in the long term. Lastly, the term involving $q_{5}$, which depends on the effective thickness $H$, allows us to properly take into account the differential drying rate of the two (bottom/top) slabs of box girders.

\subsection{FE viscoelastic formulation}

In order to take into account creep effects, we start from the classical total potential energy with an additional integration over time. Moreover, we assume the classical hypotheses of Bernoulli-Navier and firstorder beam theories, denoting with $x$ the coordinate of the beam longitudinal axis, $u(x, t)$ the longitudinal displacement, and $v(x, t)$ the transversal displacement of the generic point of the beam. Hence, $x$ defines the local axis of the beam and, in the case under investigation, it matches the global axis.

The extension of the total potential energy functional to viscoelasticity reads,

$$
\begin{aligned}
& F(u, v)=\frac{1}{2} \int_{t^{\prime}}^{t} \int_{0}^{L} R\left(x, t^{\prime}, t^{\prime}\right)\left[A\left(\frac{\partial \hat{u}(x, t)}{\partial x}\right)^{2}+\right. \\
& \left.I\left(\frac{\partial^{2} \hat{v}(x, t)}{\partial x^{2}}\right)^{2}\right] d x d t-\int_{t^{\prime}}^{t} \int_{0}^{L} p(x, t) \hat{u}(x, t) d x d t- \\
& \int_{t}^{t} \int_{0}^{L} q(x, t) \hat{v}(x, t) d x d t
\end{aligned}
$$

where $\left[t^{\prime}, t\right]$ is the time interval, $R\left(x, t^{\prime}, t^{\prime}\right)$ defines the viscous relaxation kernel evaluated at $t^{\prime}$, and $p(x, t)$ and $q(x, t)$ are the longitudinal and transversal components of distributed load, respectively; whereas, $\hat{u}(x, t)$ and $\hat{v}(x, t)$ define the solution of the auxiliary problem.

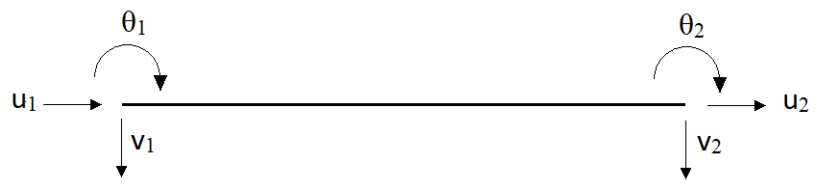

Figure 2. DoFs of a plane beam finite element

Now, among the admissible displacement fields, the solution of the viscoelastic problem, in the given time interval, is the field that makes the functional minimum. The admissible displacement fields are intended as those that satisfy both compatibility equations and the Dirichelet boundary condition.

Due to the double dimension of the integral, we need to introduce into (14) both space and time discretization. For the spatial discretization, beam finite elements with three DoFs per node are considered. Figure 2 depicts a single beam finite element with its six DoFs. In addition, 
we take into account the classical linear shape functions for the extensional DoFs $\boldsymbol{r}_{\boldsymbol{u}}=\left[\mathrm{u}_{1} \mathrm{u}_{2}\right]^{\mathrm{T}}$, and the classical cubic shape functions for the bending DoFs $\boldsymbol{r}_{v}=\left[\mathrm{v}_{1} \theta_{1}\right.$ $\left.\mathrm{v}_{2} \theta_{2}\right]^{\mathrm{T}}$. The shape functions, referring to each node of the mesh, are collected into the operator $\boldsymbol{N}(x)$ and the corresponding nodal DoFs into the vector $\boldsymbol{r}(t)$. Thus, we can express the displacement vector $\boldsymbol{u}=\left[\begin{array}{ll}u & v\end{array}\right]^{T}$ as follows:

$$
\begin{aligned}
& \boldsymbol{u}=\left[\begin{array}{ll}
\boldsymbol{n}_{u}^{T} & \mathbf{0}^{T} \\
\mathbf{0}^{T} & \boldsymbol{n}_{v}^{T}
\end{array}\right]\left[\begin{array}{l}
\boldsymbol{r}_{u} \\
\boldsymbol{r}_{v}
\end{array}\right]=\boldsymbol{N}(x) \boldsymbol{r}(t) \\
& \boldsymbol{r}(t)=\boldsymbol{A} \boldsymbol{\alpha}(t)
\end{aligned}
$$

where $\boldsymbol{A}$ denotes the coordinate transformation operator and $\boldsymbol{\alpha}(t)$ the vector of nodal DoFs. With regard to the time discretization, the vector $\boldsymbol{\alpha}(t)$ reads

$$
\boldsymbol{\alpha}(t)=\boldsymbol{M}(t) \boldsymbol{\beta}
$$

It expresses the product of time shape functions, collected into the operator $\boldsymbol{M}(t)$, and time DoFs, collected into the vector $\boldsymbol{\beta}$. For each spatial DoF, we consider two linear time shape functions, for a total of 12 DoFs per beam finite element. The first time shape function is 0 at the beginning of the time step and 1 at the end of the time step, whilst the second is 1 at the beginning and 0 at the end.

The discretized form of (14) reads

$$
\begin{aligned}
& F(u, v)= \\
& \frac{1}{2} \int_{t^{\prime}}^{t} \widehat{\boldsymbol{\alpha}}^{\boldsymbol{T}}(t)\left\{\int _ { 0 } ^ { L } R ( x , t ^ { \prime } , t ^ { \prime } ) \left[A\left(\frac{d \boldsymbol{n}_{\boldsymbol{u}}(x)}{d x}\right)\left(\frac{d \boldsymbol{n}_{\boldsymbol{u}}(x)}{d x}\right)^{T}+\right.\right. \\
& \left.\left.I\left(\frac{d^{2} \boldsymbol{n}_{\boldsymbol{v}}(x)}{d x^{2}}\right)\left(\frac{d^{2} \boldsymbol{n}_{\boldsymbol{v}}(x)}{d x^{2}}\right)^{T}\right] d x\right\} \widehat{\boldsymbol{\alpha}}(t) d t- \\
& \int_{t^{\prime}}^{t} \widehat{\boldsymbol{\alpha}}^{\boldsymbol{T}}(t)\left\{\int_{0}^{L} \boldsymbol{n}_{\boldsymbol{u}}(x) p(x, t) d x\right\} \widehat{\boldsymbol{\alpha}}(t) d t- \\
& \int_{t^{\prime}}^{t} \widehat{\boldsymbol{\alpha}}^{\boldsymbol{T}}(t)\left\{\int_{0}^{L} \boldsymbol{n}_{\boldsymbol{v}}(x) q(x, t) d x\right\} \widehat{\boldsymbol{\alpha}}(t) d t
\end{aligned}
$$

The vector $\widehat{\boldsymbol{\alpha}}(t)$ of the 'fictitious' displacement unknowns can be obtained by means of the aforementioned auxiliary elastic problem with the following longitudinal and transversal distributed loads:

$$
\begin{aligned}
& \hat{p}(x, t)=-\frac{\partial}{\partial x}\left(R\left(x, t, t^{\prime}\right) A \frac{\partial u(x, t)}{\partial x}\right)- \\
& \frac{\partial}{\partial x} \int_{t^{\prime}}^{t}\left(R(x, t, \tau) A \frac{\partial d u(x, \tau)}{\partial x}\right) \\
& \hat{q}(x, t)=\frac{\partial^{2}}{\partial x^{2}}\left(R\left(x, t, t^{\prime}\right) I \frac{\partial^{2} v(x, t)}{\partial x^{2}}\right)+ \\
& \frac{\partial^{2}}{\partial x^{2}} \int_{t^{\prime}}^{t}\left(R(x, t, \tau) I \frac{\partial^{2} d v(x, \tau)}{\partial x^{2}}\right)
\end{aligned}
$$

named 'fictitious' loads by Carini et al. (1995). Invoking the stationarity of the classical total potential energy functional, we reach the following resolving system for the auxiliary problem,

$\boldsymbol{K} \widehat{\boldsymbol{\alpha}}(t)=\boldsymbol{H} \boldsymbol{\beta}$

with $\boldsymbol{K}$ the well-known elastic stiffness operator of the assembled structure and, $\boldsymbol{H}$, an operator depending on both the relaxation kernel and the time shape functions. Hence, we can derive the vector $\widehat{\boldsymbol{\alpha}}(t)$ from (21) and, then, introducing its expression into (18), its minimum is reached when $\boldsymbol{\beta}$ corresponds to the solution of the following linear system:

$L \beta=g$

where $\boldsymbol{L}$ is the extended stiffness operator and $\boldsymbol{g}$ is the extended vector of equivalent nodal forces.

In order to specialize the solution to the case of ageing materials, it is necessary to consider a proper creep model into the formulation. For instance, according to the reasoning set out in Section 1 for box girders under investigation, the relaxation function of Model B3 (10) has to be replaced into (19) and (20). Moreover, the subdivision of the whole time step into small subintervals will further improve the proposed formulation. As a result, a sequence of smaller problems can be solved and, at every step, the calculation is accomplished by starting from the results available from previous steps. A pseudocode, summarizing the whole FE viscoelastic formulation, is reported in the Appendix.

\section{THE CASE STUDY OF THE COLLE ISARCO VIADUCT}

\subsection{Bridge structural characteristics}

The Colle Isarco viaduct is an example of segmental prestressed concrete box girder that experienced excessive multidecade deflections just after its construction. It was designed by engineers Bruno and Lino Gentilini and erected between 1968 and 1971 (Gentilini \& Gentilini, 1972). Overall, the viaduct comprises two structurally independent decks, the socalled North and South carriageways, with 13 spans, for a total length of $1028.2 \mathrm{~m}$. The main span of the viaduct, $163 \mathrm{~m}$ long, consists of two symmetric reinforced concrete Niagara box girders, which support a suspended beam of $45 \mathrm{~m}$, as depicted in Figure 3. Each box girder ends with a $59 \mathrm{~m}$-long cantilever, counterbalanced by a back arm with a length of $91 \mathrm{~m}$. Moreover, each box girder is composed of 33 box-girder cast-in-place segments with a depth varying from $10.93 \mathrm{~m}$, at the pier, 


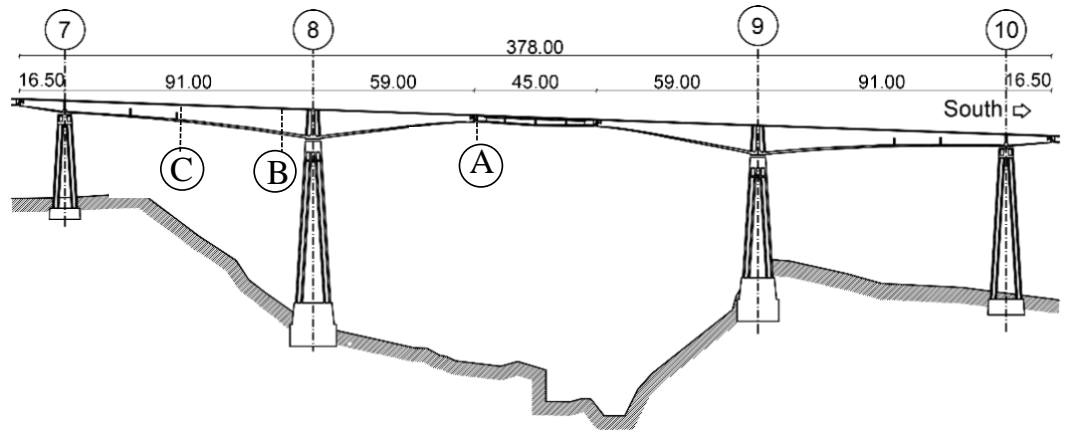

a)

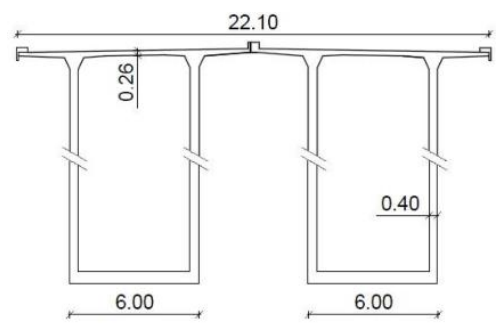

b)

Figure 3. (a) Elevation of the three main spans of the viaduct and (b) generic cross section of the box-girder. Dimensions in $\mathrm{m}$

to $2.57 \mathrm{~m}$, at the edge. The thickness of the top slab of the box girder is constant at $0.29 \mathrm{~m}$, whilst the bottom slab varies from $0.99 \mathrm{~m}$ to $0.12 \mathrm{~m}$. A concrete of nominal class $R_{c k}=450 \mathrm{~kg} / \mathrm{cm}^{2}(\mathrm{C} 35 / 45$ according to the current CEN (2004)) was used for all cast-in-place elements of piers and girders. The initial prestressing was applied through $32 \mathrm{~mm}$ diameter Dywidag ST 85/105 threaded bars, with $1030 \mathrm{MPa}$ nominal tensile strength and an initial jacking tension of $720 \mathrm{MPa}$. For each 59m-long cantilever, the longitudinal force above the pier was about $120 \mathrm{MN}$ and was provided by a total of 266 cables. As mentioned in Section 1, after only a few years from the viaduct opening, monitoring field data started to exhibit a deflection drift that cannot be explained using classical creep models such as those found in most design codes, e.g. CEN (2004). In this respect, Figure 4 depicts the deflection trend recorded at cross section A of Figure 3(a). In stark contrast with the design prediction (CEN, 2004) of $160 \mathrm{~mm}$ in 1988, the actual deflection reached $230 \mathrm{~mm}$ with an apparent rate of 8 $\mathrm{mm} /$ year. A similar behavior was also observed for the other three box girders. These first observations prompted the owner to undertake, between 1988 and 1989 , a radical intervention. Specifically, $10 \mathrm{~cm}$ of road pavement was removed from the cantilever arms and the suspended central beam, and replaced with a thinner layer of lightweight asphalt. The effect of this work is evident in Figure 4 through the immediate recovery of 70 $\mathrm{mm}$ in deflection and the disappearance of the deflection drift for a few years after the intervention. A second major maintenance activity was accomplished between 1998 and 1999, with the aim of repairing the concrete cover of the top slab, heavily deteriorated by the extensive use of salt during winter. The repair consisted of a scarification of the damaged concrete, replacement of corroded unprestressed bars, and restoration of the damaged concrete cover. In the following years, dumpy level measurements showed once more an increase in deflection drift. Therefore, another important intervention followed in 2014, which mainly involved the installation of an external post-tensioning system within the four box girders. The retrofit was designed by the Autostrada del Brennero SpA technical office in collaboration with an engineering consultant, SEICO SRL. The additional prestress was provided by a total of 212 0.6" diameter compact strands, with a jacking load of $213 \mathrm{kN}$. The additional longitudinal force produced above the pier was about $45 \mathrm{MN}$, which is almost $40 \%$ of the original prestress. To compensate the additional post-tensioning force, the thickness of the top slab of the box girder was increased from $260 \mathrm{~mm}$ to $290 \mathrm{~mm}$. This last intervention led to a recovery of $80 \mathrm{~mm}$ in deflection and a change from negative to positive deflection slope. Other minor work was carried out along with the posttensioning. Details of the retrofit work can be found in the relevant design documentation (Autostrada del Brennero SpA, 2013).

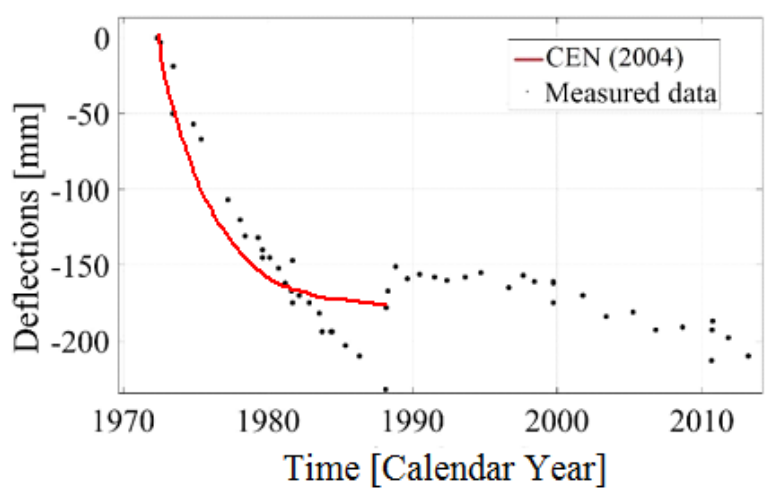

Figure 4. Comparison between monitoring data (black dots) and design prediction of CEN (2004) (red line) relevant to cross section A of Figure 3(a) 


\subsection{SHM system for field data acquisition}

The SHM system recently installed on the viaduct consists of three different sets of instruments, each based on a different technology. The first set is made of two Leica TM50 topographic total stations and 72 GPR112 prisms. It was installed and activated in early 2014, so it managed to record the effects of the retrofit intervention. The total stations can detect the position of each prism with a precision in the range of 2 to $20 \mathrm{~mm}$, every hour. The second and third set of the system were installed in June 2016 but have not yet been activated. These are made of 56 fiber optic sensors (FOSs) implementing fiber Bragg gratings (FBGs) and 74 PT100 platinum resistance thermometers connected to their respective reading units. The topographic network was designed to monitor the deflection of the decks between Pier \#7 and \#10 during the structural intervention and afterwards. The total stations were installed on a $1.50 \mathrm{~m}$-high concrete pile and protected by low-iron glass, a type of glass that minimizes the measurement error due to refraction. The location of the two stations was chosen both to ensure stability and to maximize the precision of the measurements. In general, the latter is enhanced by placing the measurement points and the benchmarks at approximately the same distance from the total stations and at the same altitude. The location of the 60 prisms used as measurement points and the 12 benchmarks is depicted in Figure 5. In order to reduce the uncertainty (Kirkup \& Frenkel 2010), 6 benchmarks were used for each total station and were positioned in sparse locations around the Isarco Valley.

The systems based on FOSs and PT100 sensors were designed to monitor the long-term effects of the recent post-tensioning intervention and to assist the investigation into possible structural anomalies. These systems record the strain of both the top and bottom slabs of the box girders and the temperature pattern between Piers \#7 and \#10. The FBGs sensors measure the average uniaxial strain with a base of $2.00 \mathrm{~m}$, whilst the PT100 resistance thermometers measure local temperature. Each instrumented section contains 4 FOSs, 2 for each deck, 1 for each slab, whilst 4 acquisition units are located near Piers \#8 and \#9. In total, 14 sections are measured using the FOSs. The temperature field is measured in 10 sections: 16 PT100 sensors, 8 for each deck, are devoted to cross sections C5 and C7, see Figure 6, whilst 6 PT100 sensors, 3 for each deck, are devoted to each of the remaining sections. The strategy consists in accurately measuring the temperature pattern in cross sections $\mathrm{C} 5$ and $\mathrm{C} 7$, and then obtaining the pattern in the remaining sections by using the temperatures provided by the 3 sensors as boundary conditions. Since the units that record data from the PT100 sensors can acquire measurements from 4 different sensors at most, 4 acquisition units are installed in cross sections C5 and $\mathrm{C} 7$, and 2, one for each deck, in the others. Each acquisition unit has an RJ-45 interface and is connected to an industrial PC by means of a TCP/IP protocol.

The total stations started acquiring data on June 9, 2014. Figure 7 shows the vertical displacement of prisms $8 \mathrm{~N} 1 \mathrm{~N}$ and $8 \mathrm{~N} 1 \mathrm{~S}$, along with the air temperature, recorded from August 4 to 9, 2014. These prisms are placed at the edge of the north girders, i.e. a location that is sensitive to variations in loads, temperature and mechanical properties. By observing these measurements, we can conclude that the behavior of the two decks before post-tensioning was similar, and mostly affected by temperature rather than live loads. Based on Figure 7, we can also argue that when the air temperature increases in the morning, the edge of each deck moves down, with a short time delay. This occurs because the source of heat, i.e. the sun, increases the temperature of the top slab more than that of the bottom slab, and so leads the top slab to elongate more than the bottom one.

In Figure 8, we show the instant effects of posttensioning. The figure displays one measurement per day, acquired from 5 am to 7 am -when a measurement exists within this interval-. Three phenomena can be observed in Figure 8:

i. from July 31 to August 11, 2014, part of the top slab belonging to the girder bearing the southbound carriageway was removed and new concrete was cast to the required thickness; this weakened the corresponding deck, leading it to behave differently from the girder bearing the northbound carriageway;

ii. from November 25 to December 3, 2014, the external cables installed in the girder bearing the southbound carriageway were tensioned, causing the same deck to rise by about $70 \mathrm{~mm}$;

iii. the behavior of the southbound deck after posttensioning in 2014 was different from the other, as its deflection clearly increased more over time than that of the northbound carriageway.

In addition, Figure 8 also shows the influence of the environmental temperature. In particular, we can notice that whereas the measurements of Figure 7 are strongly influenced by the hourly effects of the sun, which causes the edge of the cantilever to lower, the deflection displayed in Figure 8 seems to increase with the temperature. The reason for this is that measurements shown in Figure 7 were recorded before sunrise, i.e. 
when the temperature of the two slabs should be about the same and close to the average temperature of the air in the early morning. Based on this reasonable assumption, a global increase in temperature of the structure increases the size of the whole viaduct, in particular of the piers, resulting in larger measurements of the edge deflection.

Finally, Figure 8 shows that the effect of every stage of the 2014 intervention was monitored with a good precision and that measurements agree well with first principles and engineering judgement.

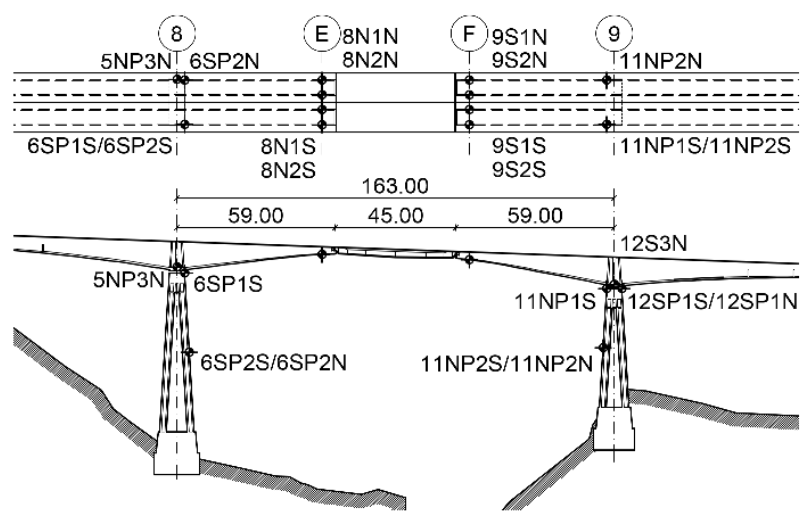

Figure 5. Configuration of prisms between Piers \#8 and \#9. Dimensions in $\mathrm{m}$

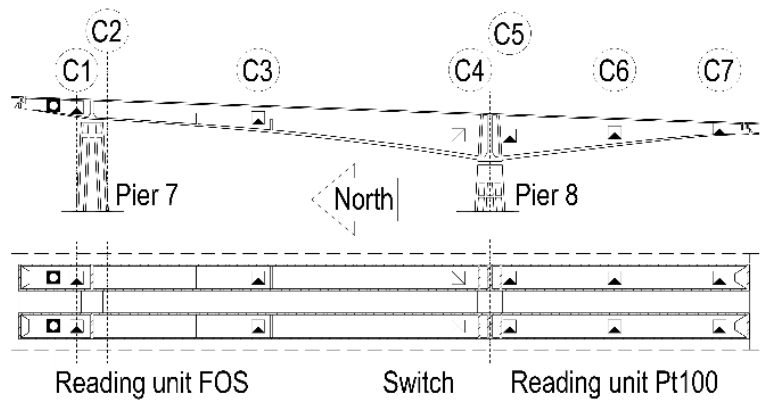

Figure 6. Configuration of FOSs and PT100 sensors

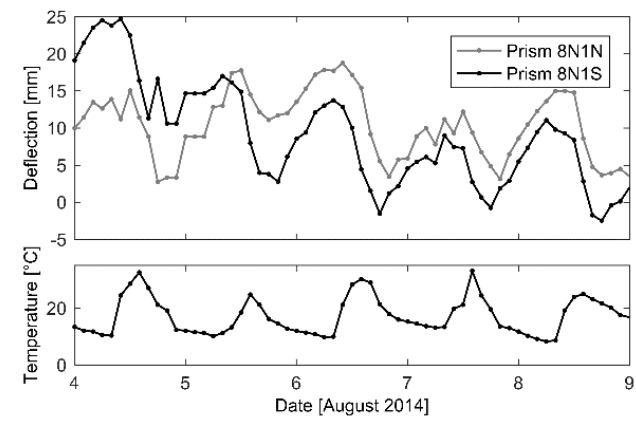

Figure 7. Time histories of deflection and temperature field data

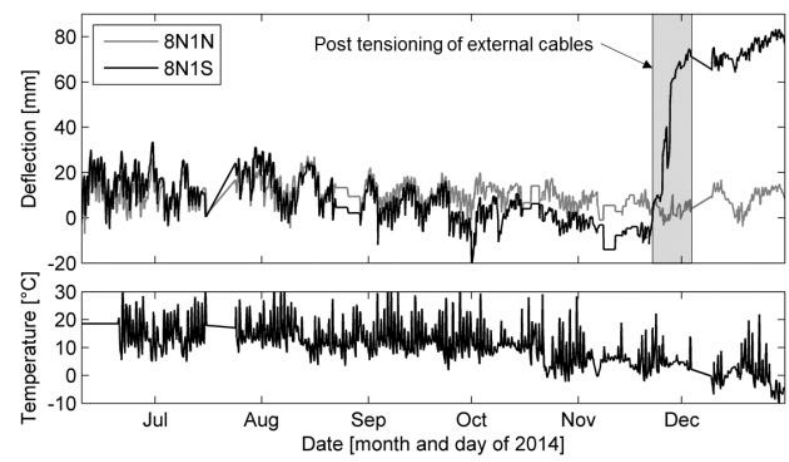

Figure 8. Measured deflection at prisms $8 \mathrm{~N} 1 \mathrm{~N}$ and $8 \mathrm{~N} 1 \mathrm{~S}$ and air temperature field data

\section{FE MODELLIIN OF THE COLLE ISARCO VIADUCT}

A realistic FE model of the Colle Isarco viaduct may be useful not only for the investigation of the main causes of its past behavior, but also to estimate future deflections, to detect the effectiveness of the last intervention, and to provide a useful means for the development of a DSS, resulting in significant cost savings in future maintenance.

Therefore, in the sequel, we present two separate FE models. The first is a refined 3D model that we used to perform local analyses only; in fact, the run time required for analyses of the whole structure appeared to be excessive. The second is a simpler 1D model, based on the formulation presented in Section 2 and conceived to perform rapid and accurate creep analyses on the main box girders. To the best of authors' knowledge, this is the first time that an energetic formulation for linear viscoelastic problems is developed and applied to a realistic structure subjected to such a complex loading history. 


\subsection{D FE model}

We developed a 3D FE model of the Colle Isarco viaduct in ANSYS v. 12.1. The concrete structure of the viaduct was implemented using SOLID186 elements, whereas the 414 cables were modeled with 8059 BEAM188 Timoshenko beam elements, for a total of 260000 degrees of freedom (DoFs). With regard to the prestressing load, each cable was placed into the model at its proper longitudinal and transversal position, simulating the prestress friction losses by applying an equivalent thermal gradient between the two edges of each cable. The geometrical characteristics considered in the model reproduce the actual geometry of the viaduct, as well as the mechanical properties of materials. We summarize both geometrical and mechanical properties in Table 1 and Table 2, where $2.38 \div 10.80 \mathrm{~m}$ indicates that the cross-section depth varies from $2.38 \mathrm{~m}$ at section A of Figure 3a to $10.80 \mathrm{~m}$ at Pier \#8 as well as for the lower slab thickness.

Table 1. Geometrical characteristics

\begin{tabular}{ll}
\hline Cross section properties & \\
\hline Cross section depth & $2.38 \div 10.80 \mathrm{~m}$ \\
Upper slab width & $11.00 \mathrm{~m}$ \\
Lower slab width & $6.00 \mathrm{~m}$ \\
Upper slab thickness & $0.26 \mathrm{~m}$ \\
Lower slab thickness & $0.12 \div 0.99 \mathrm{~m}$ \\
Lateral slab thickness & $0.40 \mathrm{~m}$ \\
\hline
\end{tabular}

Table 2. Mechanical properties

\begin{tabular}{ll}
\hline Concrete & \\
\hline Compression strength & $45 \mathrm{MPa}$ \\
Young's modulus & $31043 \mathrm{MPa}$ \\
Poisson's ratio & 0.2 \\
Density & $2500 \mathrm{~kg} / \mathrm{m}^{3}$ \\
\hline Dywidag bars & \\
\hline Yield strength & $850 \mathrm{MPa}$ \\
Young's modulus & $210000 \mathrm{MPa}$ \\
Poisson's ratio & 0.3 \\
Density & $7850 \mathrm{~kg} / \mathrm{m}^{3}$ \\
\hline
\end{tabular}

With regard to the constitutive law of Bazant, ANSYS allows users to redefine the mechanical constitutive behavior of materials through User Programmable Features (UPF). Thus, Model B3 was implemented in FORTRAN language as an external user-defined subroutine with two outputs: i) the incremental creep strain at the current time step; ii) the corresponding time derivative. According to Equations (2)-(4), these two strain quantities are functions of five parameters, which were estimated through a Bayesian analysis (Bolstad,
2010) and read: $q_{1}=19.33 \mu \varepsilon, \quad q_{2}=129.93 \mu \varepsilon$, $q_{3}=0.56 \mu \varepsilon, q_{4}=10.09 \mu \varepsilon$ and $q_{5}=19352.92 \mu \varepsilon \cdot \varepsilon_{s h \infty}$.

Regardless of the constitutive law considered in the model, ANSYS can analyze creep phenomena by means of two different integration methods.

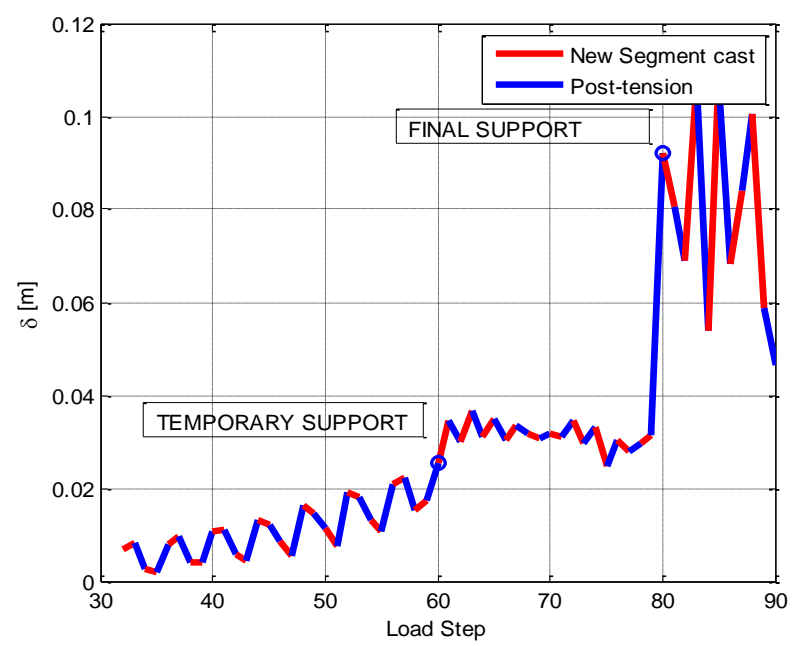

Figure 9. Phases of displacement evolution of upper point at cross section B of Figure 3(a) during construction estimated by a $3 \mathrm{D}$ FE simulation

The first is the explicit forward Euler method, whilst the second corresponds to the implicit backward Euler method. The explicit method is widely used in creep analysis because of simplicity, and its accuracy depends on the time-step size. Furthermore, it is conditionally stable, which means that its stability is restricted to small time steps. On the other hand, the implicit Euler method is numerically unconditionally stable, which implies that it does not require as small a time step as the explicit creep method, so it is much faster overall. However, the price for the unconditional stability is the need to solve non-linear equations at each time step. The computation of the creep strain, $\varepsilon^{c r}$, through the implicit integration method, i.e. the method selected for modelling the Colle Isarco viaduct, follows the algorithm summarized in Table 3. Therein, we use $n$ to indicate the current time step, $i$ the iteration step, $\boldsymbol{D}$ the derivative operator, $\boldsymbol{K}$ the stiffness operator, and $\boldsymbol{\epsilon}$ a tolerance vector.

As clearly shown in Table 3, the accuracy and effectiveness of the implicit method depend on both the chosen tolerance and the convergence ratio of the fixed point iterations. A drawback that might occur in this type of analysis concerns the slow convergence of the fixed point iterations. Therefore, if the desired accuracy is not reached within 3-4 iterations, the time-step size will be decreased and calculations repeated starting from Step 1. For instance, in the case of the Colle Isarco viaduct 


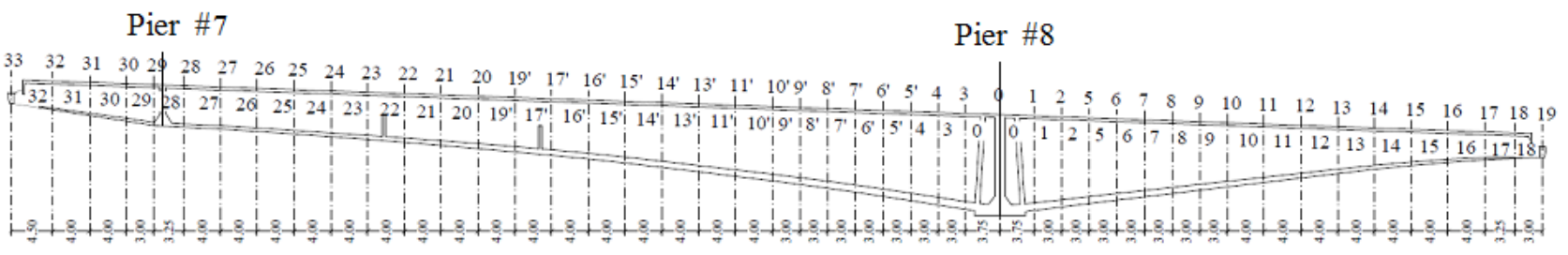

Figure 10. Discetization of the box girder under exam

model, due to the heavier deformation gradient occurring within the first few days after load application, we divided initial time steps into several small subintervals.

Table 3. Algorithm for the evaluation of creep strains implemented in the ANSYS software

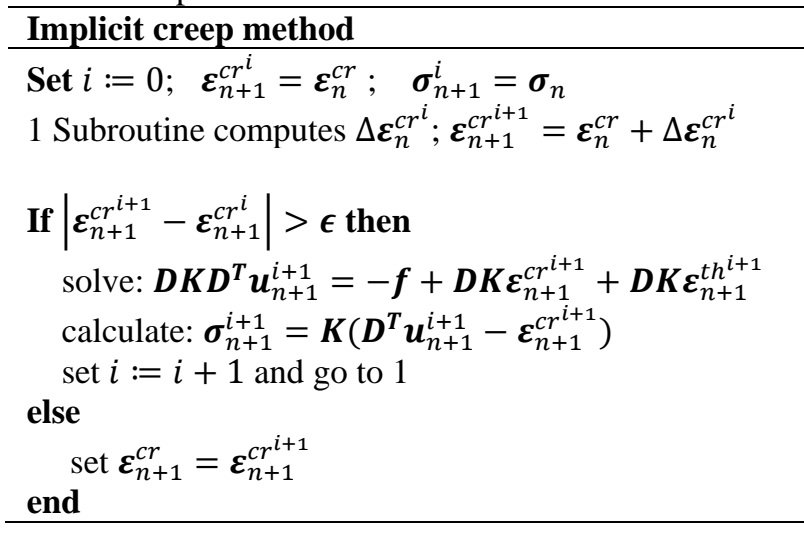

The 3D model accounts for all variations in loading, geometry and boundary conditions. Furthermore, it can reproduce both bridge history and construction stages with optimal accuracy. For instance, Figure 9 shows the principal construction phases tracked by ANSYS in terms of deflection at cross section B, specified in Figure 3(a). In particular, the box girder deck was erected in alternate segments launched each side of Pier \#8, known in the technical literature as balanced construction. As a result, after a new segment cast, indicated in red in the curve of Figure 9, the post tension followed, whose deflection is depicted in blue, in the same curve. Then, because of the different lengths of the cantilever arm (59 m) and the back arm $(91 \mathrm{~m})$, the balanced construction required the erection of a temporary support at cross section C of Figure 3(a). After the construction of the back arm, the temporary support was removed, reaching its final configuration.

We employed the same 3D FE model to perform a creep analysis from 1969 to 2016; anyhow it did not lead to satisfactory results due to: i) the huge simulation time, more than 15 days with an 8-core machine $-32 \mathrm{~GB}$ of RAM and $2.10 \mathrm{GHz}$ of CPU frequency-; ii) the amount of memory required to complete the analysis. Given this computational burden, we mainly used the ANSYS model to perform 3D elastic analyses; moreover, the extent of local stresses at the anchorage blocks of the post-tensioning systems and at other critical parts of the structure were estimated.

\subsection{D FE model}

Owing to the drawbacks of the 3D ANSYS model, the 1D model was then selected for non-linear simulations accounting for: i) the construction stages of the viaduct; ii) its geometry; iii) the prestress loadings; iv) the tension losses; v) and major maintenance work. Accordingly, we describe herein the main input data for the FE formulation anticipated in Subsection 2.2.

As depicted in Figure 10, we divided the box girder into 48 segments. Hence, 49 nodes, with three DoFs per node, characterize the 1D FE model, for a total number of 147 DoFs against the 260000 DoFs of the 3D model. In order to take into account the exact assembly of the segments and the change of constraint configuration, we redefine the geometric input data at each time step within the interval 0 days (start of construction on May 1969) to 731 days (end of construction on May 1971), with a timestep size equal to 1 day. After the construction end, the static configuration of the box girder was left unchanged. Thus as depicted in Figure 3(a), the final configuration of each single box girder consists of a roller at Pier \#7 and a pin at Pier \#8.

Other important input data provide information about the number of upper and lower pretensioning cables, the homogenized area, the homogenized moment of inertia, and the volume-to-surface ratio at each cross section of mesh; all assigned according to the technical reports of Autostrada del Brennero SpA. In detail, the area and moment of inertia are two fundamental quantities for the determination of the element stiffness operator $\mathbf{K}^{\mathrm{e}}$, whereas the volume-to-surface ratio is utilized to compute the drying compliance of Model B3. All additional information useful for estimating the five parameters of Model B3 through Equations (5)-(9), i.e. cement content, aggregate content, water content, environmental relative humidity, and other mechanical properties of materials, are directly included into the 
MATLAB code. As previously discussed, we reassigned these geometric input data, i.e. number of cables, area, moment of inertia, and volume-to-surface ratio, at each time step within the first 731 days and during the last maintenance work in 2014. For instance, Table 4 collects geometric input data and information about the Model B3 parameters at Pier \#8, where ' $\mathrm{o}$ ' indicates the characteristics of the old concrete C35/45 and ' $n$ ' indicates the characteristics of the new layer of concrete C45/55 added at the top of the upper slab during the last maintenance work (2014). In addition, it is important to underline that we set the final values of Model B3 parameters through a proper calibration process; it was accomplished by varying the main quantities related to shrinkage phenomena, i.e. relative humidity and volumeto-surface ratio. Since they are taken into account by parameter $\mathrm{q}_{5}$, it affected the most the creep response of the structure.

Table 4. Geometrical characteristics and Model B3 parameters of the cross section at Pier \#8, where 'o' indicates the characteristics of old concrete and ' $n$ ' indicates the characteristics of the new layer of concrete

\begin{tabular}{lc}
\hline Characteristics of the cross section at Pier $\mathbf{~ 8}$ \\
\hline Cross section depth & $10.80 \mathrm{~m}$ \\
Upper slab width & $11.00 \mathrm{~m}$ \\
Lower slab width & $6.00 \mathrm{~m}$ \\
Upper slab thickness & $0.26 \mathrm{~m}$ \\
New upper slab thickness & $0.09 \mathrm{~m}$ \\
Lower slab thickness & $0.99 \mathrm{~m}$ \\
Lateral slab thickness & $0.40 \mathrm{~m}$ \\
Number of upper cables & 260 \\
Number of lower cables & 0 \\
Homogenized area & $18.13 \mathrm{~m}^{2}$ \\
Homogenized inertia & $340.43 \mathrm{~m}^{4}$ \\
Volume-surface ratio (o) & $0.22 \mathrm{~m}$ \\
Volume-surface ratio (n) & $0.09 \mathrm{~m}$ \\
$q_{1, o}$ & $19.33 \mu \varepsilon$ \\
$q_{2, o}$ & $143.90 \mu \varepsilon$ \\
$q_{3, o}$ & $1.07 \mu \varepsilon$ \\
$q_{4, o}$ & $9.22 \mu \varepsilon$ \\
$q_{5, o}$ & $323.47 \mu \varepsilon$ \\
$q_{1, n}$ & $17.41 \mu \varepsilon$ \\
$q_{2, n}$ & $101.43 \mu \varepsilon$ \\
$q_{3, n}$ & $0.75 \mu \varepsilon$ \\
$q_{4, n}$ & $6.99 \mu \varepsilon$ \\
$q_{5, n}$ & $304.79 \mu \varepsilon$ \\
\hline
\end{tabular}

Table 5. Load history at Pier \#8 during main interventions

\begin{tabular}{lll}
\hline Date & $\mathbf{M}[\mathbf{k N ~ m}]$ & $\mathbf{P}[\mathbf{k N}]$ \\
\hline $16 / 05 / 1971$ & $-8.66 \cdot 10^{5}$ & $1.09 \cdot 10^{5}$ \\
$15 / 03 / 1988$ & $-7.06 \cdot 10^{5}$ & $9.94 \cdot 10^{4}$
\end{tabular}
$24 / 11 / 2014$ $-7.60 \cdot 10^{5}$
$9.64 \cdot 10^{4}$
$04 / 10 / 2015$
$-7.60 \cdot 10^{5}$
$1.40 \cdot 10^{5}$

Both the dead loads and the prestress loads were assigned at each time step. A total of 1373 time steps were assigned until year 2040, in terms of bending moment $\mathrm{M}$ and concentrated force $\mathrm{P}$. Table 5 reports the load history of the cross section at Pier \#8 relative to the dates of main interventions. Moreover, in order to guarantee the compatibility of displacements between the old and new slab after the intervention of 2014, we considered a horizontal force applied at the interface. We evaluated this horizontal force by simply subtracting the increment of creep-shrinkage deformation of the new layer to the increment of creep-shrinkage deformation of the old upper slab; then, we multiplied this difference by the Young's modulus and the cross section area of the new layer.

\subsection{D model validation and prediction}

In this section, we discuss the validation of the 1D FE formulation through comparison between field data and the simulated time-deflection profile. Moreover, we also present the prediction made by the 1D model.

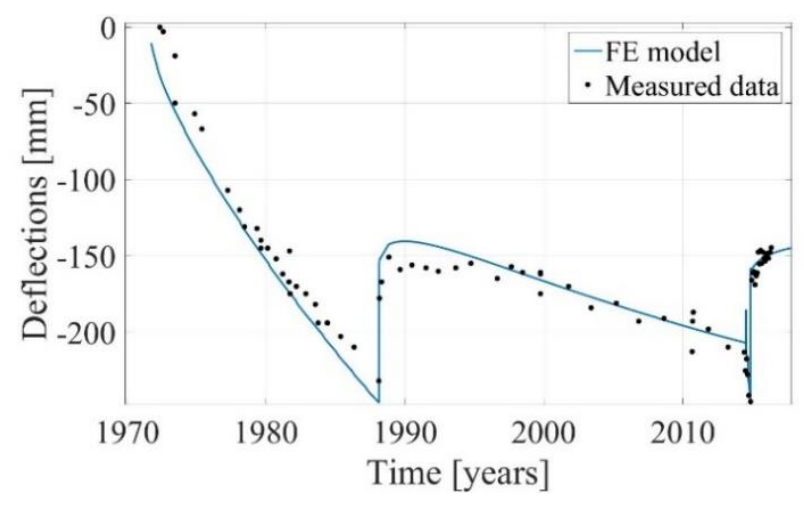

Figure 11. Comparison between 1D FE model predictions and field data of time-deflection profile relevant to cross section A of Figure 3(a)

With regard to model validation, Figure 11 depicts the deflection trend at cross section A of Figure 3(a), from the construction of the viaduct in 1969 up to 2016 . The first part of the simulation curve is characterized by a slope very similar to the one acquired by dumpy level measurements. We can also observe a high level of accuracy in reproducing the elastic recoveries during the two maintenance interventions, in 1988 and 2014, respectively. A slight deviation between field data and the FE model occurs from 1989 to 1996; however, this 
mismatch vanishes a few years after 1996. Overall, we estimated a RMSE equal to $5.7 \%$ between the results of 1D FE model and measured field data. Therefore, it is evident that the proposed FE model can capture the past behavior of the viaduct with a favorable accuracy.

The comparison between field and model data during the last maintenance work can be better appreciated in Figure 12; more precisely, deflection values decrease in sign before the post-tensioning of November 2014 and increase afterwards, at a rate of $7 \mathrm{~mm} /$ year from December 2014 to September 2016. Obviously, this deflection increase will reduce over the years due to both tension losses and reduction in the differential shrinkage between top and bottom slabs. As a result, the 1D FE model predicts a horizontal configuration of crosssection A around November 2025 with a limited decrease up to 2040. The relevant FE analysis from 1969 to 2040 requires 8 hours, with an 8-core desktop machine, $32 \mathrm{~GB}$ of $\mathrm{RAM}$ and $2.10 \mathrm{GHz}$ of $\mathrm{CPU}$ frequency.

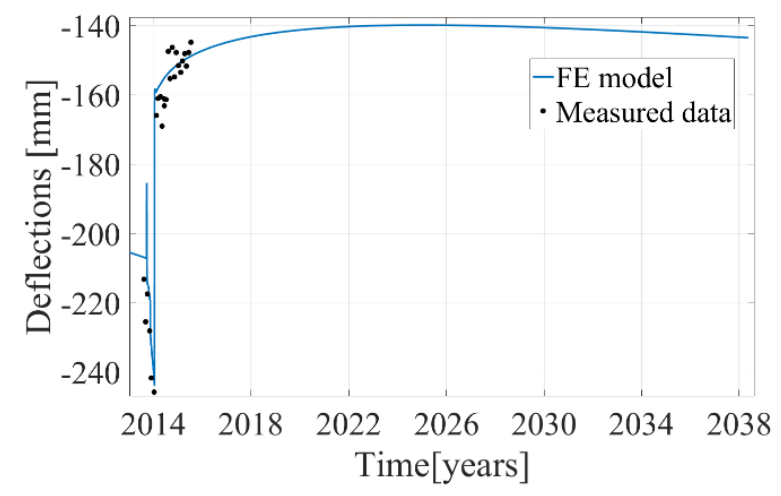

Figure 12. Deflection effects after the intervention of 2014 and prediction until 2040 relevant to cross section A of Figure 3(a)

It is then evident that the $1 \mathrm{D}$ model requires a lower computational effort than the model involved in the ANSYS 3D analysis, briefly described in Subsection 4.1. The relevant main reasons are: i) the reduced number of DoFs; ii) the integration method used to compute creep strains; and iii) the time-step size required for the analysis. In fact, as most of commercial software, ANSYS software evaluates the creep strain $\boldsymbol{\varepsilon}_{n}^{c r}$ through the backward Euler method performing an iteration process at each time step $n$, as summarized in Table 3 . On the other hand, no iteration process is required in the proposed 1D formulation, mainly because of the linearity of the problem and the update of both $\boldsymbol{L}$ and $\boldsymbol{g}$, see Equation (22), at each time step. In addition, the 1D formulation allows for the use of larger time steps than the backward Euler method, guaranteeing accurate results nonetheless. Another limitation of the backward Euler method regards its accuracy, which depends on the time-step and the convergence ratio of the fixed point iterations. Conversely, the accuracy of the 1D FE formulation also depends on the order of the chosen time shape functions collected in $\boldsymbol{M}(t)$ of Equation (17). In other words, if we perform 1D and 3D analyses with the same time-step size, the choice of higher order shape functions in the 1D model can guarantee a better accuracy. Moreover, the presented 1D FE model, implemented in MATLAB and based on the energetic formulation presented in Subsection 2.2 seems to be particularly effective for the simulation of the Colle Isarco viaduct, including its history. Notwithstanding that, the proposed model neglects shear deformations, which is acceptable considering the slenderness of the structure, i.e. the incidence of bending deformations.

\section{DEVELOPMENT OF A DECISION SUPPORT SYSTEM}

In this section, we propose a general scheme of DSS for the Colle Isarco viaduct, in which information coming from the 1D FE model are also involved. As depicted in Figure 13, the proposed DSS consists of two main parts: i) Bayesian logic (Sivia \& Skilling, 2006; Bolstad, 2010, Han et al., 2017) to compute probabilities of structural states that may occur; and ii) axiomatic Expected Utility Theory (EUT) (Neumann \& Morgenstern, 1944) (Raiffa \& Schlaifer, 1961) to identify economically optimal choices. To the best of authors' knowledge, no DSS based on EUT has yet been proposed for everyday use in the field of civil engineering. Indeed, a recent publication by Faber \& Maes (2008) pointed out a number of issues arising when optimal decision-making has to be implemented in reallife settings for management of structures and infrastructures. Conversely, DSSs already operational in the real life can be found in fields of medicine and finance (Mussi, 2004; Sauter, 2010), as the probabilities of different scenarios and the financial consequences can be easily assessed.

The DDS proposed herein takes as inputs four variables:

i. The most recent SHM measurements, $\mathbf{y}$, which, in our case, are the displacements from the total stations, the strains from the FOSs and the temperatures from the PT100 sensors;

ii. the prior probability $p(\boldsymbol{\theta})$ of the parameters $\boldsymbol{\theta}$ that define the structural state, i.e. Young's modulus of concrete, initial prestress and relative humidity;

iii. the prior probability $p(S)$ of possible structural conditions, i.e. 'pristine' and 'damaged'; 
iv. the costs $\mathbf{C}$ corresponding to each possible event, i.e. costs of using a damaged structure -including indirect costs- and costs of inspection.

The DSS contains a Bayesian inference module and a decision-analysis module. In order to calculate the probability $p(S \mid \mathbf{y})$ of each possible state of the viaduct, given the updated observations $\mathbf{y}$, the former module implements a numerical Bayesian inference such as the Metropolis-Hastings algorithm (Cappello et al., 2015) and Monte Carlo importance sampling (Evans \& Swartz, 1995). In order to identify the economically optimal choice $a_{\text {opt }}$ for the detected structural behavior, the decision-analysis module takes into account costs $\mathbf{C}$, (Cappello et al., 2016). Typical choices to be considered are: 'do nothing', 'close the bridge' and 'send an inspector'. The optimal action $a_{\text {opt }}$ corresponds to the maximum expected utility, calculated by applying the EUT axioms.

In this framework, the 1D FE model proposed in Subsection 4.2 is used to train the Bayesian inference module depicted in Figure 13. The objective of the Bayesian module is to identify which structural condition $S$-'pristine' or 'damaged'- agrees with the measurements best; therefore, it must contain the response predicted by the FE model in both conditions. During training, the structural behavior is simulated using the FE model for different realizations of structural condition $S$ and for different realizations of state parameters $\boldsymbol{\theta}$. The need to perform a number of simulations that is significant from a statistical viewpoint made it necessary to develop an extremely efficient structural model. Straub (Straub, 2014) estimated that $10^{2}$ to $10^{3}$ simulations are required to accurately calculate structural reliability. Relevant simulation results are stored in a lookup table, which provides the structural response of the viaduct for the realizations of $S$ and $\boldsymbol{\theta}$ not considered during training. The use of a lookup table reduces the execution time of the Bayesian inference algorithm within the DSS, and therefore, expedites the identification of the optimal action $a_{\mathrm{opt}}$ that is recommended to the bridge manager.

\section{CONCLUSIONS AND FUTURE PERSPECTIVES}

In this paper, we have presented the conception and development of effective FE-based tools to model, in general, segmental prestressed concrete box girders susceptible to creep and, in particular, the significant Colle Isarco viaduct. We have also shown the recordings from the structural health monitoring system recently installed on the viaduct, thus highlighting its key role in both model validation and interpretation of the structural behavior of the viaduct.

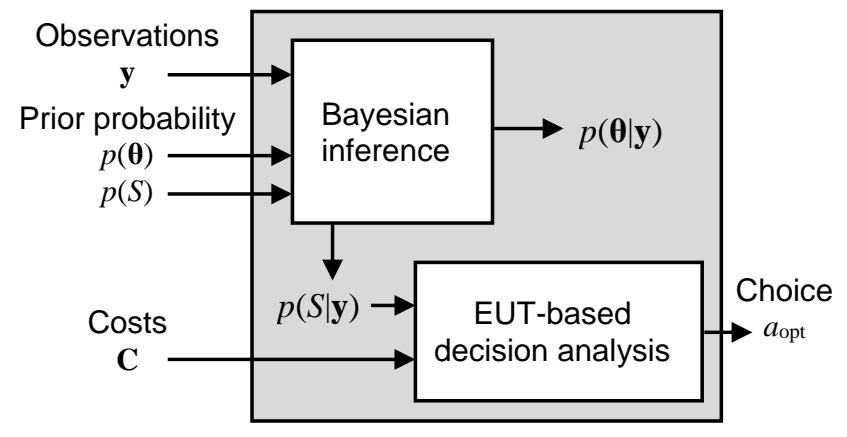

Figure 13. The architecture of the decision support system

Two different FE models of the Colle Isarco viaduct were presented, both based on the creep constitutive law proposed by Bazant and co-workers. The first is a 3D FE model developed in a commercial software, utilized to perform elastic analyses only, due to the excessive simulation time required to perform creep analyses. The second is a 1D FE model conceived through an energetic formulation for linear viscoelastic problems, used to estimate the deflection trend at the tip of the longest cantilever, from viaduct construction in 1969 up to 2040. Unlike the 3D FE model, the 1D FE formulation relies on an extension of the classical total potential energy and is particularly convenient for accomplishing creep analyses mainly due to its reduced run time. Furthermore, it simulates the past behavior of the viaduct with a good level of accuracy and provides a satisfactory prediction of its long-term behavior up to 2040, with a clear change in the deflection trend at the end of 2025. The results of the 1D FE model were validated using both field data from the old dumpy level acquisition method until 2013 and from the new structural health monitoring system, afterwards. Moreover, the structural health monitoring system not only provides accurate and reliable data for validation of the proposed 1D FE model, but also successfully records the response of the viaduct during the last maintenance work in 2014.

The obvious exploitation of both the 1D FE model and monitoring field data, presented above as an effective tool for future risk estimation and viaduct management, is their use into the context of Bayesian inference for the implementation of an efficient decision support system. Finally, further run time savings can be achieved in the 1D FE model by parallelizing the algorithm solution for different load applications and by replacing the 5parameter Bazant model creep constitutive law with three parameters fractional-based real-order operators. 


\section{ACKNOWLEDGMENTS}

The work presented in this paper was carried out under the research agreement between Autostrada del Brennero SpA/Brennerautobahn AG and the University of Trento. The financial contribution of Autostrada del Brennero is acknowledged. The authors also wish to thank all those who contributed to this project, in particular C. Costa, W. Pardatscher, P. Joris, S. Vivaldelli, (Autostrada del Brennero SpA); M. Vivaldi (SEICO srl); A. Bonelli, D. Trapani (University of Trento).

\section{APPENDIX}

In this appendix, we summarize the FE viscoelastic formulation presented in Subsection 2.2 by means of the following pseudocode.

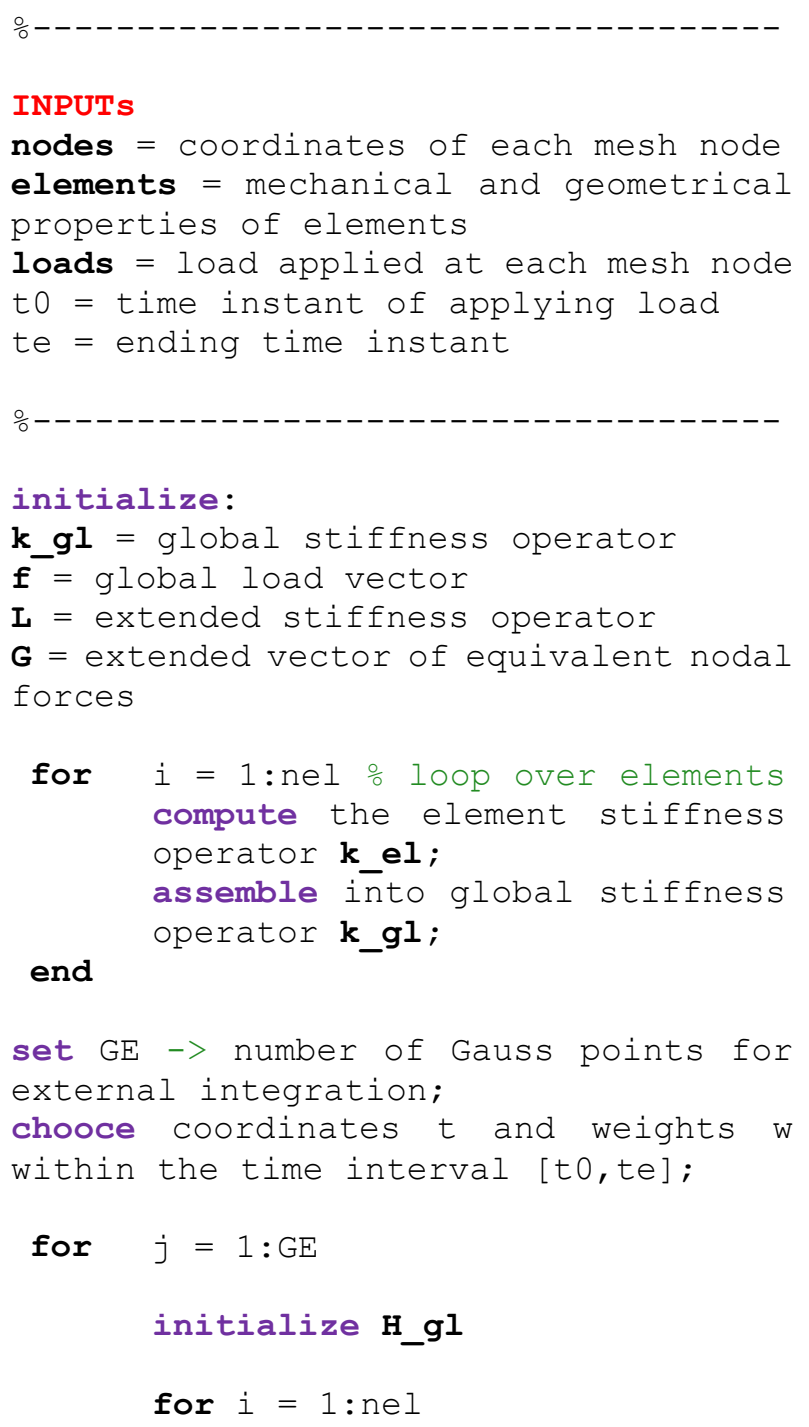

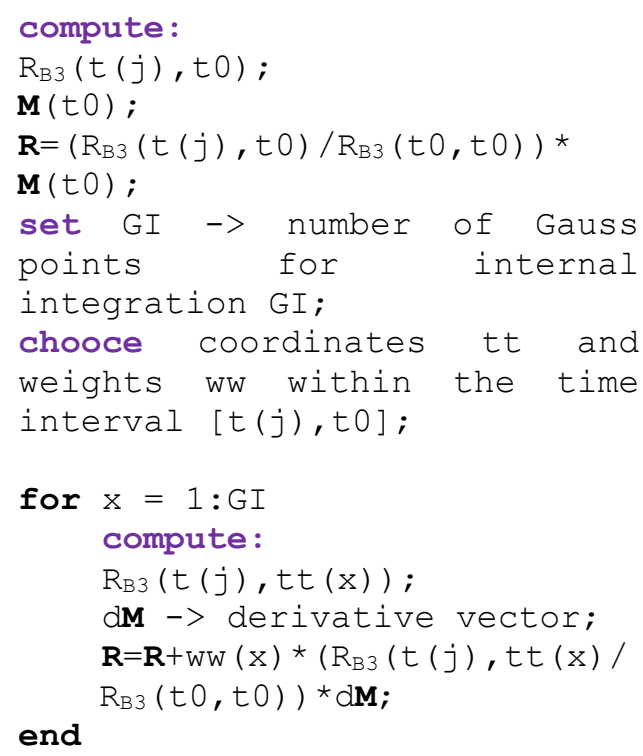

\section{REFERENCES}

ANSYS Academic Research, Release 12.1.

Autostrada del Brennero SpA. 2013. Consolidamento strutturale dell'impalcato del viadotto colle isarco, a progressiva $\mathrm{km}$ 8+957. Relazione tecnica. Technical report (in Italian).

Bazant, Z. P., and Kim, S. S. (1979). "Approximate relaxation function for concrete". Journal of the Structural Division, 105(12), 2695-2705.

Bazant, Z. P. \& S. Baweja. (1995). "Creep and shrinkage prediction model for analysis and design of concrete structures - model B3". Materials and Structures, 28(6), 357-365. 
Bazant, Z. P., Q. Yu and G. Li (2012). "Excessive Long-Time Deflections of Prestressed Box Girders. I: Record-Span Bridge in Palau and Other Paradigms". Journal of Structural Engineering, 138, 676-686.

Bazant, Z. P., Mija Hubler, Milan Jirásek (2013). "Improved Estimation of Long-Term Relaxation Function from Compliance Function of Aging Concrete". Journal of Engineering Mechanics, 139(2), 146-152.

Balageas, D., C.P: Fritzen, A. Guemes. (2010). Structural Health Monitoring. John Wiley \& Sons.

Beltempo, A., C. Cappello, D. Zonta, A. Bonelli, O.S.Bursi, C. Costa, W. Pardatscher. (2015). "Structural Health Monitoring of the Colle Isarco Viaduct". IEEE Workshop on Environmental, Energy and Structural Monitoring Systems (EESMS).

Bolstad, W. M. (2010). Understanding Computational Bayesian Statistics. New York City: Wiley.

Cappello, C., Zonta, D., Pozzi, M., \& Zandonini, R. (2015). "Impact of prior perception on bridge health diagnosis". Journal of Civil Structural Health Monitoring, 5(4), 509-525.

Cappello, C., D. Zonta, and B. Glisic (2016). "Expected Utility Theory for Monitoring-Based Decision-Making". Proceedings of the IEEE, 104(8), 1647-1661.

Caracoglia, L., S. Noè, and V. Sepe (2009). "Nonlinear Computer Model for the Simulation of Lockin Vibration on Long-Span Bridges". Computer-Aided Civil and Infrastructure Engineering, 24, 130-144.

Carini, A., P. Gelfi, and E. Marchina (1995). "An energetic formulation for the linear viscoelastic problem. part I: Theoretical results and first calculations". International Journal for Numerical Methods in Engineering, 38(1), 37-62.

CEB (Comité Euro-International du Béton) (2008). CEB-FIP model code 1990. London: Thomas Telford Ltd.

CEN (European Committee for Standardization) (2004). Eurocode 2: Design of concrete structures - Part 1-1: General rules and rules for buildings.

Di Paola, M. \& M. Zingales (2012). "Exact mechanical models of fractional hereditary materials". Journal of Rheology, 56, 983-1004.

Di Paola, M., F. Pinnola, and M. Zingales (2013). "Fractional differential equations and related exact mechanical models". Computer and Mathematics with Applications, 66, 608-620.

Evans, M., \& Swartz, T. (1995). Methods for approximating integrals in statistics with special emphasis on Bayesian integration problem. Statistical Science, 10(3), 254-272.
Faber, M. H. \& M. A. Maes (2008). "Issues in societal optimal engineering decision making". Structure and Infrastructure Engineering, 4(5), 335-351.

Gentilini, B. \& L. Gentilini (1972). "Il viadotto di Colle Isarco per l'Autostrada del Brennero." L'Industria Italiana del Cemento, 5, 318-334 (in Italian).

Glisic, B. \& D. Inaudi (2007). Fiber Optic Methods for Structural Health Monitoring. Chichester: John Wiley \& Sons.

Han, B., Xiang, T-Y and Xie, H-B, (2017). "A Bayesian inference framework for predicting the longterm deflection of concrete structures caused by creep and shrinkage", Engineering Structures, 142, 46-55.

Kirkup, L. \& R. Frenkel (2010). An introduction to uncertainty in measurement. Oxford: Cambridge University Press.

MATLAB Release 2015b, The MathWorks, Inc., Natick, Massachusetts, United States.

Mazzoni, S. OpenSees command language manual. PEER Center, 2006

Mussi, S. (2004). Putting value of information theory into practice: a methodology for building sequential decision support systems. Expert Systems, 21 (2), 92103.

Neumann, J. \& O. Morgenstern (1944). Theory of Games and Economic Behavior. New York, NY, USA: Wiley.

Raiffa, H. \& R. Schlaifer (1961). Applied Statistical Decision Theory. Boston, MA, USA: Clinton.

Shapiro, K. A. (2007). Finite-Element Modeling of a Damagd Prestressed Concrete Bridge. Doctoral Thesis, Auburn University.

Sauter, V. L. (2010). Decision Support Systems for Business Intelligence. New York City: Wiley.

Sivia, D., \& Skilling, J. (2006). Data Analysis: a Bayesian Tutorial. Oxford: Oxford University Press.

Straub, D. (2014). Value of information analysis with structural reliability methods. Structural Safety, 49, 7485.

Torbol, M., H. Gomez, and M. Feng (2013). "Fragility Analysis of Highway Bridges Based on Long-Term Monitoring Data". Computer-Aided Civil and Infrastructure Engineering, 28, 178-192.

Wendner, R., Zdenek Bazant, Mija Hubler (2015). "Statistical justification of Model b4 for multi-decade concrete creep using laboratory and bridge databases and comparisons to other models". Materials and Structures, 48, 797-814. 